\title{
Pharmacovigilance on biologicals and biosimilars: a Danish perspective
}

\author{
Benedicte Lunddahl, DVM
}

The development of biological medicinal products is in
rapid growth and as patents for reference products expire, new biosimilar products become available. This has a marked impact on several stakeholders; from patients and physicians to decision-makers, and on activities; from treatment of patients to the conduct of pharmacovigilance. The Danish Medicines Agency (Laegemiddelstyrelsen, DKMA) has increased its focus on the pharmacovigilance of biologicals and is implementing an action plan jointly with a working group comprising representatives from the Danish Medical Association, the pharmaceutical industry and the five Danish Regions.

Keywords: Biological medicinal products, biosimilars, national competent authority, pharmacovigilance

\section{The Danish healthcare system}

Denmark is a small Scandinavian country of about 5.5 million people. The country is politically divided into five Regions responsible for the governance of public hospitals across the country. The Danish healthcare system is financed via income taxes and generally, treatment and medication provided by public hospitals are free of charge to Danish citizens. To ensure equal treatment possibilities and rational use of healthcare budgets, a national council for the use of expensive hospital medicines (Rådet For Anvendelse Af Dyr Sygehusmedicin, RADS) makes recommendations on which medicinal products should be used in the hospitals. The supply of medicinal products to Danish hospitals follows a tendering process, which usually covers a 12-month period.

Infliximab as an example In April 2015, RADS announced that they find biosimilar infliximab equal to the original reference product (Remicade) in efficacy and safety. Based on this, RADS made a recommendation to use the less expensive infliximab product. At that point, Remsima was the less expensive infliximab product available in Denmark and currently still is. Remsima won the national tendering process for infliximab and was consequently supplied to all hospital pharmacies in Denmark in the summer of 2015.

Generally, the hospitals took up the recommendation from RADS that Remsima could be given both to treatment-naïve patients and to patients who were already on Remicade, unless there were scientifically justified reasons not to do so. According to legislation, the treating physician decides which medicinal product should be prescribed and administered.

Consequently, the uptake of Remsima increased rapidly as more and more patients were switched from Remicade to
Remsima, and new patients started treatment on Remsima. In the first quarter of 2016, Remsima covered around 97\% of infliximab consumption in Denmark.

\section{A dream scenario?}

This might seem like a dream scenario, as it would obviously save money for the healthcare system while ensuring the same benefits for the patients, but the reality was a bit more complex. Soon after the switch, patients started expressing their concern regarding the new infliximab product, i.e. Remsima, and approached their physicians for an explanation and to seek assurance. However, the physicians did not seem comfortable about explaining the principle of biosimilarity; hence, the patients remained uncertain about the change that had been introduced in their treatment.

Patient anxiety was further aggravated by the fact that hospitals and Regions in Denmark had put out different information on biosimilars on their websites, and that some Danish scientific societies had issued a slightly different statement compared to the announcement from RADS.

\section{The action plan}

Consequently, patients' organizations approached the Ministry of Health, voicing their concerns, and the Ministry responded by setting up the action plan in partnership with the Danish Medicines Agency (Laegemiddelstyrelsen, DKMA); Action Plan on Biological Medicines, Biosimilars and Vaccines for 2015-2016.

The focus on biologicals is increasing because this type of medicinal products is in rapid development - new biological 
medicinal products are continuously being developed offering new or improved treatment options within growth hormones, cancer, diabetes and arthritis. At the same time, development of more biosimilar medicines is expected when patents for the reference products expire in the years ahead. The aim of the action plan is to ensure targeted and product-specific monitoring of biologicals. It focuses on four key areas: - undertaking activities to encourage monitoring of biologicals at product level

- carrying out information activities to improve healthcare professionals' understanding of product-specific monitoring and 'peace of mind' among patients when using the products

- offering digital solutions at hospitals and in medical practices to ease adverse drug reaction reporting from healthcare professionals

- increasing focus within the DKMA on monitoring the safety of using biologicals and biosimilars.

The action plan is being implemented jointly by the DKMA and a working group comprising representatives from the Danish Medical Association, the Danish Association of the Pharmaceutical Industry, the Danish Generic Medicines Industry Association, the Danish Association of Parallel Importers of Medicine, and the five Danish Regions.

\section{First initiatives}

The action plan also builds on the EU Pharmacovigilance legislation, which places several obligations on the Member States, including taking appropriate measures to clearly identify any biological medicinal product that is the subject of a suspected adverse drug reaction (ADR) report, with due regard to the brand name and batch number.

This obligation was recently implemented in Denmark through the amendments to two executive orders, which came into effect on 1 January 2016. The aim of the revised executive orders is to increase focus on the monitoring of the use and safety of biological medicinal products, including any adverse reactions that occur when switching between biosimilar and reference medicinal products. One amendment of an executive order implies that healthcare professionals shall make records of the brand name and batch number in patient health records when prescribing any biological medicine. The other amendment of an executive order makes it mandatory that healthcare professionals include, to the extent possible, the brand name and batch number when reporting suspected ADRs. Both executive orders cover certain biologicals listed on the DKMA website. The list focuses on new biologicals and products where a biosimilar is available on the Danish market and so is a dynamic list that will be updated ad hoc.

Furthermore, to encourage ADR reporting on a product level a pop-up message has been implemented in the electronic reporting forms to encourage submission of brand name and batch number.

\section{Dialogue with stakeholders}

Another initiative carried out relates to the second focus area; raising awareness on biosimilarity through targeted information. To identify information gaps from a patient perspective, invitations went out to the patient organization for rheumatoid arthritis, colitis, Crohn's, psoriasis, sclerosis, Danish Cancer Society and Danish Patients, and a meeting was held during the autumn of 2015. Along with providing a clearer picture of what kind of information was requested by Danish patients in relation to treatment with biological medicinal products the meeting also investigated which communication methods would be most suitable to engage with patients and relatives. The dialogue with patients and patient organizations showed that their focus is on having peace of mind and maintaining quality of life and stability in treatment, including continuing to have the drug through the same route of administration and avoiding new kinds of side effects. Furthermore, patients want dialogue with healthcare professionals and to have a say in their own treatment course. It was agreed that information was needed to clarify similarities and differences between biological reference products and biosimilars, specifically in relation to side effects and route of administration. The information should come from neutral authorities and should be available before treatment start and on several platforms.

Information was made available on the DKMA website, and leaflets and short information videos have been produced to inform about similarities and differences between biologicals and biosimilars, including batch variation, and that switching from one to the other should not cause changes in treatment response. In addition, it was highlighted that patients can report suspected ADRs themselves through an electronic reporting form on the DKMA website.

Communication activities targeted at physicians were also carried out to inform about the new legal requirements, the list of selected biologicals and to raise awareness about the uncertainties patients may feel. Information, flyers, including leaflets to patients, were made available to hospitals and physicians via emails to all hospital CEOs, regional drug committees and relevant scientific medical colleges as well as being published on the DKMA website.

In relation to efforts to ease reporting of ADRs from hospitals and general practices, the DKMA has made available a webservice on a national service platform to enable data transmission from local electronic health record (EHR) systems to the DKMA; however, as there are many different electronic systems for health records across the country, the integration to local systems has to be built locally. This part of the action plan falls under the responsibility of the Danish Regions, as they run the hospitals in Denmark.

\section{Work in progress}

The ADR reports submitted to the DKMA are continuously evaluated with a particular focus on any pattern possibly related to switching from the reference product to biosimilar infliximab and to review if product names and batch numbers are provided.

The action plan on biologicals and biosimilars will be evaluated by the end of 2016 .

\section{Competing interests: None.}

Provenance and peer review: Commissioned; internally peer reviewed.

DOI: 10.5639/gabij.2016.0503.030

Copyright @ 2016 Pro Pharma Communications International 